\title{
Decisiones judiciales referidas al comercio electrónico en la Argentina desde el derecho de consumidores y usuarios
}

\section{Decisions on Electronic Commerce and Consumer Rights in Argentina}

Carlos Eduardo Tambussi*

http://dx.doi.org/10.21503/lex.v16i22.1651

* Abogado, Universidad de Buenos Aires (1991). Profesor adjunto regular: Universidad de Buenos Aires, Facultad de Derecho. Cátedra: Dr. Roberto Saba. Asignatura: Derechos Humanos y Garantías. Profesor a cargo del curso Protección Constitucional de Consumidores y Usuarios del Ciclo Profesional Orientado en la Facultad de Derecho (UBA). Presidente de la Comisión de Derecho del Consumidor de la Asociación de Abogados de Buenos Aires. Autor de libros y de numerosos artículos en revistas de la especialidad nacionales y extranjeras.

Correo electrónico: cetambu@uolsinectis.com.ar
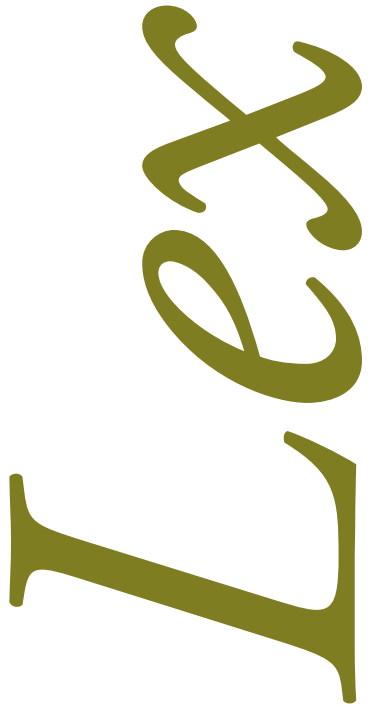


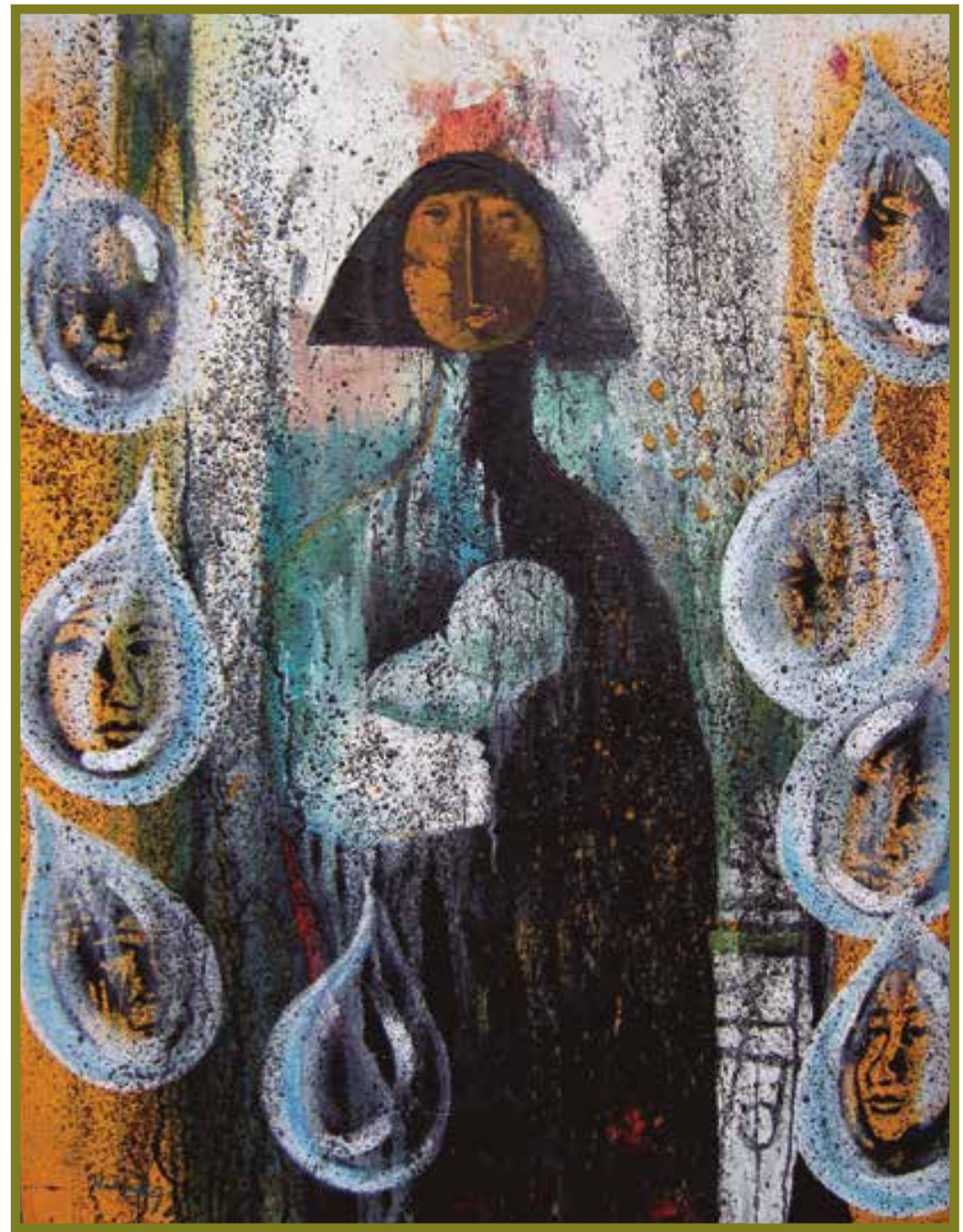

Tengo sed II. Pintura. Juan Carlos Nananake. 


\section{RESUMEN}

El presente trabajo reseña los principales fallos de los tribunales argentinos, dictados contemporáneamente con la vigencia del Código Civil y Comercial de la Nación, y aun anteriores, donde se incorporan las primeras normas nacionales regulatorias del comercio electrónico en el marco de los contratos de consumo y especialmente dirigidas a los derechos de los consumidores en lo que respecta a la responsabilidad por daños de los llamados "portales de venta", la jurisdicción aplicable, el ejercicio del derecho de arrepentimiento y las interpretaciones desde el derecho administrativo sancionatorio. En esos aspectos se aprecia una tendencia con algunos retrocesos al avance en la protección del consumidor, a la par que se aprecia con mayor claridad la necesidad de mayor precisión regulatoria y normativa específica, para continuar en el camino de regulación de esta manera cada vez más generalizada de realizar actos de consumo, y para muchos bienes y servicios, la única posibilidad.

Palabras clave: Código Civil y Comercial de la Nación, comercio electrónico, responsabilidad de los portales de venta, derecho al arrepentimiento, derecho administrativo sancionatorio.

\section{ABSTRACT}

This paper reviews the main rulings of the Argentine courts, dictated contemporarily with the validity of the Civil and Commercial Code of the Nation, and even earlier, where the first national regulatory rules of electronic commerce are incorporated within the framework of consumer contracts and especially directed to the rights of the consumers regarding the responsibility for damages of the so-called "sale portals", the applicable jurisdiction, the exercise of the right of repentance and the interpretations from the sanctioning administrative right. In these aspects, there is a tendency with some setbacks to the advance in consumer protection, at the same time that the need for greater regulatory precision and specific regulations can be seen more clearly, in order to continue in the way of regulation in this way more and more. generalized to perform acts of consumption, and for many goods and services, the only possibility.

Key words: Civil and Commercial Code, electronic commerce, regulation, responsibility of the sales portals, right to repentance, administrative sanctioning law. 


\section{INTRODUCCIÓN}

En los últimos años se han generalizado cambios muy profundos en la forma en que los consumidores adquieren bienes y servicios, siendo el factor informático y la contratación por Internet las nuevas estrellas del ya desequilibrado mundo de los contratos de consumo. El estimulante es la comodidad, la posibilidad de trascender las fronteras y hacer compras internacionales, y en algunos casos también la rapidez, en estos momentos en donde tratando de ganarle al tiempo en todo, nos sujetamos a él con mayor energía. Este enfoque hace que la defensa del consumidor en la contratación electrónica deba ser vista con mayor celo, y quizá hasta con normativa específica.

El Código Civil y Comercial de la Nación Argentina recepta la metodología del derecho comparado, sistematizando separadamente los contratos negociados fuera del establecimiento comercial y los contratos a distancia. En los primeros suele haber técnicas agresivas de comercialización frente a un consumidor desprevenido, y en los segundos, la posición desfavorable del consumidor tiene otro cariz, ya que Este no entra en contacto con el producto sino con lo que de él se le ofrece, no pudiendo comprobar la relación de correspondencia entre ello y lo que finalmente recibirá.

Conforme el art. 1105, son contratos a distancia "aquellos concluidos entre un proveedor y un consumidor con el uso exclusivo de medios de comunicación a distancia, entendiéndose por tales los que pueden ser utilizados sin la presencia física simultánea de las partes contratantes. En especial, se consideran los medios postales, electrónicos, telecomunicaciones, así como servicios de radio, televisión o prensa”.

Con lo que, a partir de la vigencia del nuevo cuerpo normativo, se incorporan aspectos altamente beneficiosos para la consolidación del régimen tuitivo consumidor, entre los que se encuentra la regulación de la contratación electrónica.

Se ha expresado que "nadie puede dudar que el comercio electrónico haya revolucionado la actividad económica al favorecer, al facilitar el acceso a informaciones, la prestación de ser- 
vicios y la obtención de productos sin necesidad de desplazamiento por parte del consumidor al establecimiento comercial. Esta fascinante, fantasmagórica ilusión que se abre, gracias a la Internet, permite por un lado, que el proveedor reduzca sus costos, lo cual puede provocar abaratamiento en el valor de los productos y servicios, y por el otro, simétricamente, puede ocasionar además de las inseguridades jurídicas, un ahondamiento, una exposición de las debilidades, de las vulnerabilidades de quienes, como los consumidores, se encuentran en una situación de inferioridad técnico-económica, con respecto a los expertos, no profanos". ${ }^{1}$

Es en esa inteligencia que la normativa de la unificación recepta esa realidad, incorporando regulaciones que aparecen como necesarias e imprescindibles para los tiempos actuales y las características de contrataciones que marchan hacia su generalización y muchas veces son la única posibilidad de contratar ciertos negocios o servicios.

Por este sistema, tanto la negociación como la conclusión de la contratación y el pago se efectúan electrónicamente, manifestándose el consentimiento a través del teclado, debiendo el consumidor adherir a extensas condiciones generales (términos y condiciones), lo cual hace aplicable al caso el fenómeno regulador de los contratos de adhesión ya que todo el sistema responde al criterio de organización del proveedor a través de su sitio web.

Entendemos que es un error entender que en la venta electrónica no necesariamente existe debilidad subjetiva del consumidor. Se necesitan ciertas cualidades para afrontar la contratación on line, por lo que la debilidad natural del protagonista de este derecho estaría agravada en estas modalidades. Tampoco que no exista el factor sorpresa, por ser el consumidor el que toma la iniciativa. La ingeniería de las implementaciones de estos contratos es capaz de superar las habilidades informáticas medianamente desarrolladas, y las sorpresas quizá no surjan de la iniciativa que las excluye, sino a posteriori de la invitación a contratar, en cuanto a las puestas en marcha de las etapas o aperturas de pantallas diseñadas hábilmente por el proveedor para concretar el negocio primariamente propuesto, o tal vez otro.

Estas contrataciones se realizan en circunstancias donde resulta dificultoso comprender las características, significados, costos, y aspectos fundamentales de aquello que se está contratando, máxime teniendo en cuenta que en este tipo de técnicas de venta el consumidor solo percibe promesas del servicio o imágenes del producto sin poder verificar cómo es en la realidad. ${ }^{2}$ A la vez, importan tratamiento de datos personales y tarjetas de crédito por parte

Véase Sara Lidia Feldstein de Cárdenas, “Desprotección del consumidor transfronterizo. Hitos en el derecho latinoamericano contemporáneo”, La Ley (18/03/2015):1.

2 "El consumidor solo conoce el bien o servicio adquirido por la información (verbal o gráfica) que le es brindada por el proveedor, por lo que el producto real que en su oportunidad recibirá puede o no coincidir con la idea que de él se ha formado el adquirente; esta circunstancia justifica brindarle una opción de dejar sin efecto el vínculo, para el caso de que no se adecue el objeto de contratación a sus expectativas". José Fernando Maximiliano Calderón y Rafael Márquez, "El arrepentimiento en el derecho del consumo", La Ley (2009-C): 742. 
del proveedor, que implican un significativo desequilibrio para el consumidor, que se advierte con solo constatar el exceso de confianza que el proveedor impone que se le dispense al exigir estos datos, y los riesgos del consumidor al suministrarlos.

A más de lo apuntado, esa avasalladora catarata de posibilidades de consumo en la web es factor generador de inseguridad en el consumidor respecto a la identidad y la seriedad del proveedor con el que está tratando, y de dudas respecto al cumplimiento efectivo de las obligaciones derivadas del negocio, ${ }^{3}$ pero la certeza que debe pagar primero por él. De ahí que esta modalidad sea una fuente generadora de alta problemática de abusos, pero no siempre de reclamos.

De la internacionalidad de este sistema, que convierte al mundo en un verdadero "mercado global" " se desprenden también otros aspectos que la jurisprudencia ha tenido que tratar, respecto de la problemática de la jurisdicción aplicable en los casos de comercio electrónico.

\section{LA RESPONSABILIDAD DE LAS PLATAFORMAS DE VENTA}

\section{El caso Claps ${ }^{5}$}

a. Los hechos: Los hechos versan sobre el caso de una persona que adquiere dos entradas para un recital a través del sitio de Internet de Mercado Libre, para regalárselas a sus hermanos. Las entradas se adquieren en ese sitio, donde eran ofrecidas por otra persona, que en el caso fue citada como tercero, y habían sido originalmente ofrecidas por la empresa Ticketek. Los boletos habían sido denunciados como robados por esta empresa, y sin embargo, vendidas en la plataforma. Varias personas que intentaron ingresar con esas entradas fueron demoradas y detenidas, entre ellos los actores del presente caso en comentario. Solamente un oferente de las entradas en el sitio, tercero citado en la causa, fue condenado en primera instancia, no así el portal de ventas.

b. La responsabilidad del proveedor del "espacio de intercambio": El sentenciante de grado se basó en que el adquirente reconoció haber leído, entendido y aceptado los términos y condiciones generales del uso de la página web de Mercado Libre (tal como sabemos que es costumbre en estos sitios, como paso previo a utilizar el sistema, la exigencia de leerse extensas "letras chicas", que inmediatamente deben 'clickearse'

3 Véase Verónica Gilbota Landriel, "El comercio electrónico y la defensa del consumidor”, DJ (10/11/2010): 1.

4 Véase Federico M. Álvarez Larrondo, "El consumidor a partir del Proyecto de Código Civil”, RCyS (2013-III): 5.

5 Cámara Nacional de Apelaciones en lo Civil, sala K "Claps, Enrique Martin y otro c. Mercado Libre S. A. s/daños y perjuicios”, 05/10/2012, cita online: AR/JUR/55788/2012. Véase nuestra opinión en Carlos Tambussi y Lucrecia Córdoba, "Y los libres mercados responden (A propósito de los sitios de compraventa en Internet)", Microjuris (21/12/2012): MJDOC-6121-AR | MJD6121. 
como aceptadas). No contento con esta aceptación de rendición incondicional, la decisión de grado deja solo al consumidor. Entiende que este realizó la compra por su propio riesgo, la ejecutó por su cuenta, ya que para acceder se necesita establecer la propia clave y usuario en la página de Mercado Libre y el autor del regalo sabía que el portal no es dueño de los productos que se venden, que tuvieron que ser adquiridos directamente del tercero citado y oferente de las entradas. Para así decidir, el juez hace mérito de una pericia que informa que tanto oferente como comprador deben registrarse en la página, donde cada usuario declara ser el único responsable por los artículos que publica para su venta y por las ofertas que realiza. Los compradores no le pagan a Mercado Libre sino al oferente, y Mercado Libre no garantiza la veracidad de la publicidad de terceros que aparezca en su sitio.

En síntesis, el consumidor fue abandonado a merced de la adhesión a un sistema predispuesto, mal interpretado por el magistrado, que considera a la página como un espacio virtual que se brinda a la gente, y permite que se comuniquen por Internet para vender o comprar servicios o bienes. Casi una sociedad de beneficencia, altruista, feliz porque la gente intercambie, y autora de unas cláusulas predispuestas que la autoeximen de toda responsabilidad dado que no es propietaria ni oferente de lo que se vende, por lo que no habría relación de consumo entre Mercado Libre y los que adquieren productos por su intermedio. Olvidó el digno magistrado que la ya casi veinteañera Ley de Defensa del Consumidor contempla como cláusulas abusivas a aquellas que desnaturalizan las obligaciones a cargo de una de las partes o aquellas que limiten la responsabilidad del proveedor por daños, tipos en los que justamente incurren las condiciones generales de Mercado Libre. Felizmente el grave error es subsanado por la alzada, siendo sus ejes decisorios los siguientes:

No cabe duda de que Mercado Libre presta un servicio, y como sociedad anónima lo realiza con fines de lucro. Es, sin lugar a dudas, un proveedor en los términos del art. 2 de la Ley de Defensa del Consumidor 24240. En este caso, la plataforma pone al alcance de un número indeterminado de posibles clientes registrados los bienes y servicios que otros producen. La Cámara reseña varios conceptos de proveedor para concluir en que la entidad que nos ocupa no está excluida de esta categoría.

Por ende, responderá en caso de que la prestación no llegue a cumplirse en el marco de la responsabilidad solidaria del art. 40 de la Ley de Defensa del Consumidor, y sin perjuicio de las acciones de regreso entre los corresponsables. Por este tipo de responsabilidad, y atento a su carácter objetivo basado en el "riesgo de empresa" o "riesgo de actividad económica" y en el lucro, toda vez que allí donde hay beneficios originados en una actividad, debe generarse la contrapartida de responsabilidad por los riesgos y los costos, es decir que le cabe al proveedor soportar las contingencias que su iniciativa 
importa, como contrapeso de los beneficios. Dentro de estos riesgos, suele incluirse específicamente a la responsabilidad derivada de daños causados por productos y servicios defectuosos. ${ }^{6}$

Para llegar a este aserto es llamativamente interesante cómo se interpreta la misma pericia informática que valoró el magistrado de grado, de la cual se extraen conclusiones diferentes, completas, verdaderas, del negocio de la empresa finalmente condenada. De la misma experticia surge que si se concreta la venta, Mercado Libre le factura al vendedor una comisión, y hay también un cargo por publicación al mismo personaje. Dice textualmente el decisorio que "el servicio que presta la accionada resulta de beneficio económico para sí”. Luego explica que en base a las comisiones, se establece el precio final de la operación, pero todo es realizado mediante la cesión de un espacio publicitario clasificado y el cobro de comisiones de venta, por lo que resulta palmario que no es cierto que Mercado Libre disponga de toda esa estructura de manera totalmente desinteresada.

Tiene claro la Cámara que se celebra un contrato electrónico, al cual se le aplicarán las reglas de todos los contratos, y de importar una relación de consumo, será objeto de la protección del régimen tuitivo consumidor. Y para mayor abundamiento, se señala que el tipo de contratación electrónica no solo no atenúa la responsabilidad de los proveedores que lo utilizan, sino que por el contrario la agrava en virtud del mayor conocimiento que la utilización de la tecnología requiere, creándose así una profesionalidad más severa y un aumento de la desigualdad y la vulnerabilidad del consumidor.

La empresa se ofrece como un ámbito de confianza y crea la apariencia de un ámbito de contactos o de relaciones con la cual dice no vincularse ni responsabilizarse, pero sobre los que impone condiciones para que puedan participar del sistema. En un párrafo señero, la alzada manifiesta que "esa confianza es precisamente la fuente primaria de sus obligaciones", y seguidamente, "que también lo es de sus ganancias" y por ende será solidariamente responsable con los otros sujetos integrantes de la red atento a su posición de intermediario.

c. Conclusión: ${ }^{7}$ El precedente que comentamos ratifica el criterio de responsabilidad objetiva que como derivación del aspecto protectorio rige en materia de derechos del

6 Sergio Sebastián Barocelli, "Los sujetos expuestos a una relación de consumo", DJ (11/05/2011): 1.

El estudio de este caso puede complementarse con un decisorio que responsabiliza al mismo portal por falta de identidad entre lo ofrecido y lo entregado (Cámara 4a . de Apelaciones en lo Civil y Comercial de Córdoba, 29/12/2016, "Mercado Libre SRL c. Dirección de Defensa del Consumidor y Lealtad Comercial s. re. Apel”, en Diario La Ley, 08/03/2017: 11) y con otro precedente donde se aplican las reglas de mandato para analizar la relación entre el cliente del portal y el medio de pago impuesto por este, conforme a las condiciones generales aceptadas y también impuestas (Cámara en lo Civil y Comercial de Jujuy, sala III, 15/09/2016, "F.P c. Mercado Libre SRL s. acción emergente de la ley del consumidor", en La Ley On Line, cita AR/JUR/67450/2016). 
consumidor, y encuadra — con justicia — la tarea de una actividad lucrativa dentro de aquellas responsables frente al consumidor. En el supuesto bajo análisis, se hace justicia respecto a un portal de Internet que lucra con la publicidad y las comisiones de las transacciones que se hagan, y que es responsable por permitir que esas publicidades incumplan las previsiones de la ley en materia de garantías, a la vez que impone abusivas cláusulas que lo eximen de responsabilidad, fuera de las previsiones legales.

\section{Un retroceso. "El caso Kosten"}

El precedente que analizamos, es un fallo de la sala D de la Cámara Nacional de Apelaciones en lo Comercial, que debe resolver un tema de daños y perjuicios planteados contra Mercado Libre SRL por la falta de entrega de un rodado adquirido en ese famoso sitio de internet, dedicado al comercio electrónico de bienes y servicios de toda especie. Se llega a la alzada en derrota para el actor, ya que el juez de grado rechazó la demanda con costas. Anticipamos el significado del decisorio como el de un retroceso protectorio que soslayó la existencia de relación de consumo y de responsabilidad objetiva en este caso.

a. El fallo y sus argumentos: El actor afirma en la causa haber pagado el auto mediante transferencias de dinero internacionales por intermedio de la gestión de una empresa local, indicada por Mercado Libre a tales fines, más una suma en concepto de gastos. Pese a ello, el vehículo nunca le fue entregado. Reclama en consecuencia, la devolución de lo pagado, el daño moral y peticiona por la aplicación de multa civil (daño punitivo) en términos del art. 52 bis de la ley 24240 .

La estrategia procesal del sitio de internet es la habitual, intentando desligarse. Opone así excepción de falta de legitimación pasiva, definiéndose a sí misma como una plataforma de ventas y subastas on line de bienes registrables y no registrables. Siendo el caso perteneciente a la primera especie, donde los datos del oferente se publican en el sitio, la carta de presentación de la empresa se completa con una asimilación a la de los viejos avisos "clasificados" de los diarios papel, hoy en vías de extinción: para sí misma Mercado Libre es un facilitador de contactos, un acercador de la oferta y la demanda, que si deciden vincularse lo hacen en forma independiente, convirtiendo al sitio en un espacio neutral a las partes, conforme dice lo advierten en los términos y condiciones que se presentan a los interlocutores antes de comenzar las contrataciones. Contestando demanda en subsidio, la empresa argumenta que el demandante interactuó con un supuesto vendedor, quien usó todo tipo de artilugios, hasta el de

8 Cámara Nacional de Apelaciones en lo Comercial, Sala C "Pérez Morales, Gonzalo Martín c/ Booking.com Argentina SRL y otros s/ ordinario", 10/08/2017. En DPI, Suplemento Consumidor, Nro. 129 del 29 de agosto de 2017. Ver nuestra opinión en Carlos Tambussi, "Relación de consumo y responsabilidad objetiva entre los usuarios de las plataformas de venta y el proveedor del servicio", La Ley (22/05/201): 2. 
hacerse pasar por representante de Mercado Libre. En ese marco, la maniobra fue posible por la negligencia, ligereza o imprudencia del actor, que se ve evidenciada en el intercambio habido de correos electrónicos, donde por la defectuosa redacción debió haberle generado sospechas. Dentro de esa ingenuidad considera incluido el haber hecho el pago sin conocer a la persona destinataria y sin constatar la condición jurídica del auto. Sigue planteando que Mercado Libre no cobró comisión alguna y que los gastos pagados por el actor se refieren a la publicación del aviso en la sección clasificados, a lo que también fue inducido por el presunto vendedor. Concluye rechazando la responsabilidad en términos del art. 40 de la ley 24240, que considera no comprendida entre los supuestos de responsabilidad objetiva, por lo que el actor debió haber demostrado la negligencia o culpa de Mercado Libre, configurándose en el caso la culpa de un tercero por el cual esta no debe responder.

b. La alzada: El tribunal de apelación considera como generalidades a los agravios de la actora fundados en relación los principios del derecho del consumidor, la asimetría, el valor de la confianza en el comercio electrónico, para pasar a afirmar que la cuestión del caso es más compleja que esos temas. Continúa expresando que a falta de un "plexo normativo especial relacionado con la responsabilidad de los prestadores de mercados electrónicos, el caso se va a resolver con base en el derecho comparado, mediante instituciones de otras comarcas con desarrollo jurídico similar al nuestro. Pero más allá de la cita doctrinaria, seguidamente el voto se refriere a directivas del Parlamento Europeo y del Consejo, en particular la 2003/31/CE respecto a los prestadores intermediarios. Estas se refieren al almacenamiento de datos, y explica que han sido aplicados por el Tribunal de Justicia de la Unión Europea a los prestadores de internet que facilitan intercambio entre oferta y demanda, y que pretenden restringir los casos en que conforme al derecho de los países pueda generarse responsabilidad de los prestadores de este tipo de servicios, definiendo una zona libre "a favor de los proveedores" que los coloque "al amparo de la inseguridad jurídica que se deriva de la posible aplicación de otros regímenes de responsabilidad”. Tenemos, entonces, un sinceramiento respecto a quién venimos a considerar especialmente. Es así que según el desarrollo argumental, hay que analizar si el operador de la plataforma ha tenido una posición neutra entre las partes - mediante un tratamiento meramente técnico y automático de los datos - o si ha tenido conocimiento de hechos o circunstancias que revelen el carácter ilícito de la información, y no haya retirado la misma o impedido el acceso. En suma, si la empresa es un "mero canal”, no puede exigírsele conocimiento y control de la información almacenada.

La línea de razonamientos continúa con la imposibilidad de imponer a los prestadores de servicios una obligación genérica de supervisar los datos, ya que son meros alojadores "sin obligaciones proactivas", cuestión que nuestra Corte Suprema recogió al anali- 
zar la responsabilidad de los "motores de búsqueda": así, a la inexistencia de obligación de supervisar, sigue inexistencia de responsabilidad. De esa forma considera que el sistema de comercio electrónico se está estructurando de forma tal que su base es el "desempeńo diligente" del programa prestacional, sin que el operador deba asegurar el resultado de los negocios que se celebran por ese medio. Para el caso en que quede involucrado un consumidor, la alzada señala que solo la prueba de la participación activa del operador del mercado electrónico podría generar su responsabilidad en términos del art. 40 ley 24240, dado el riesgo que se deriva de esa especial configuración del servicio, pero no lo generará si ese papel activo no se puede demostrar, y con ese limitado alcance correspondería admitir la responsabilidad objetiva como sucedió en los casos como "Claps", entre otros. Culmina el razonamiento respecto al papel de los operadores como Mercado Libre en este caso: estas empresas no se obligan a mediar en negociar o concluir negocios, sino que permiten acceder a información para la consecución de una finalidad, que es adquirir productos o servicios, obteniendo una retribución por esa tarea. Ofrecen, además, actividades conexas como seguros, evaluaciones, medios de pago, verificación de identidad, etc. Para esas actividades no es extensible la exención de responsabilidad, que se restringe solo al almacenamiento de datos, y tampoco para aspectos relacionados con la protección de datos personales. De modo que todo depende de la forma en que se diseña el servicio, por lo que la cuestión queda para analizar en la casuística. Y a la luz de la prueba rendida, entiende que la demandada fue un simple sitio de alojamiento de datos o "hosting". Considera acreditada la accesibilidad al sistema mediante la lectura de los "términos y condiciones" donde la demandada se exime de responsabilidad y participación, y la no necesidad de registro previo o creación de usuario o clave para ingresar y que el aviso del rodado contenía el nombre y teléfono de la parte vendedora. Nada evidencia que Mercado Libre tuvo papel activo o posibilidad de conocimiento o control de los datos almacenados y publicitados. Fue solo un foro de transacción, cumpliendo con el estándar del deber de información cierta, clara y detallada, en cuanto a los riesgos que corren los consumidores. Nada acredita que Mercado Libre hubiera tenido conocimiento de la ilicitud, o siquiera sospechas, no habiendo intervenido motores de búsqueda. Agrega que el vendedor fue inhabilitado en fecha anterior a la compra, y que no se mantuvo la oferta con posterioridad a la inhabilitación, siendo la operación posterior a la misma. Invoca que pese a los avisos respecto a que la empresa no envía correos electrónicos, el actor mantuvo por esa vía comunicaciones con el actor del ilícito, respecto de los cuales la plataforma de Mercado Libre fue completamente ajena. Destaca además que el pago se realizó mediante otra empresa y no mediante la ofrecida por la demandada. Finalmente, tampoco Mercado Libre cobró comisión alguna, conforme surge de la prueba pericial. En este marco, el actor ha sido víctima de su propia torpeza. Debió haber verificado la situación jurídica y física del rodado, y tomar los recaudos nece- 
sarios al efectuar un pago a un residente en el extranjero. No le llamó la atención, además, que el precio del rodado sea notoriamente menor al vigente en el mercado, y como señalamos antes, el lenguaje de los correos electrónicos.

Los aspectos que nos hacen disentir con esta decisión son los siguientes:

a) Los proveedores, aun ocasionales, en términos de la ley 24240 y actualmente del art. 1093 del Código Civil y Comercial, ante la necesidad de ejercer exitosamente el proceso de distribución de productos, acuden a otras empresas que realicen dichas funciones de manera especializada. Ante esta situación, nace la necesidad para las empresas de utilizar intermediarios que realicen tareas que no están a su alcance, como la llegada masiva al universo de consumidores. Para los efectos de la ley 24240, el intermediario es proveedor y comprendido dentro del sistema de distribución y comercialización de los productos. Por ende, el portal Mercado Libre protagoniza una relación de consumo, concepto más amplio que el de contrato, cuando se ofrece un bien o servicio a través de su espacio. Le son aplicables al caso los principios interpretativos a favor del consumidor, el sistema de responsabilidad y las demás cuestiones procesales y de fondo propias del régimen tuitivo. En ese marco no es admisible que imponga cláusulas por las cuales unilateralmente se desresponsabilice por las relaciones conectadas a través del portal o por la veracidad y exactitud, exhaustividad o autenticidad de los datos proporcionados por los usuarios.

b) En el caso, además de lo señalado, la Cámara ha soslayado que Mercado Libre cobra por la publicación, y comisión por la concreción de los negocios, aunque este último aspecto no se ha dado en autos. No obstante, la operación no podría haberse concretado sin la intermediación del "proveedor de servicios", quien recepta la oferta, la publicita, pone en contacto a la potencial compradora con la vendedora y posibilita el intercambio. No hay consideración en el fallo cobro por la publicación, aun dentro de la alusión al concepto de "clasificados". Hay por parte de Mercado Libre una facilitación de la transacción económica, de la operación, que se basa en la confianza y en la apariencia que ofrece la aparición en esa plataforma. Eso es lo que la distingue de un clasificado de "diario papel", que contenía avisos dentro de un medio dedicado a la empresa periodística. En este caso el sitio tiene como rigurosa especialidad, y esa es su marca y su sesgo, la venta por internet y es usado masivamente. Quien acude a esas plataformas lo hace con el valor confianza' ${ }^{9}$ como valor asociado a la rapidez y

9 "El sistema comercial que ofrece Mercado Libre propone a sus usuarios, la mayoría novatos de conocimiento digital, que entren a una Web Site en la cual todo parece tan sencillo como apretar unos cuantos botones del teclado y acceder a un universo de bienes y servicios. El consumidor, dentro de ese espacio, tiene la razonable expectativa de que lo que ocurre allí está controlado por el proveedor en el cual confía. Pero, ciertamente, no es así. Los riesgos que corre son grandes, y lo ignora; esa ignorancia o desinformación es lo que constituye la infracción al artículo $4^{\circ}$ de la ley 24.240" (véase Resolu- 
la accesibilidad de las ofertas, en ese mismo orden. En esa línea, no compartimos el criterio de la Cámara al exigir que el actor tenga una especialidad en el negocio de los autos y por eso tendría que haber tomado las precauciones del caso, tales como verificar previamente la situación física y jurídica del auto. El riesgo aparece claramente con la publicación de la venta de un auto a precio irrisorio. Nada de eso se dice en el fallo. Es deber del proveedor del servicio de plataforma controlar esos ofrecimientos.

c) El fallo se basó también en que al actor le fueron brindados con la claridad suficiente los términos y condiciones generales del uso de la página web de Mercado Libre (tal como sabemos que es costumbre en estos sitios, como paso previo a utilizar el siste$\mathrm{ma}$ ), pero a la par se invoca que para la sección clasificados no es necesario registrarse. De esta inconsistencia, pero a la vez de este hecho insoslayable, es que entendemos queda claro que sin la intervención del portal la operación no habría sido posible. No es un simple facilitador, es condicionante y presupuesto de la transacción. ${ }^{10}$ Es gracias a sus servicios que los contenidos llegan a manos de los usuarios. Tal, el servicio que presta, tal lo que lo hace proveedor y responsable en términos de la ley 24240 y el Código Civil y Comercial de la Nación. Hay una peligrosa traslación del régimen de responsabilidad subjetiva al mundo del consumo, que parte de la base de - sin decirlo- no considerar proveedor al portal de intercambio. El fallo dice que solo se es responsable por la adquisición del efectivo conocimiento del ilícito que se hace a partir de hechos o circunstancias aptos para posibilitar por inferencias lógicas ese carácter. Y no solo niega que Mercado Libre la haya tenido por el precio irrisorio, sino que da vuelta el sistema de responsabilidad, requiriéndose acreditar la ignorancia premeditada o ignorancia culpable. No juega la ilicitud de los datos en sí (o su presunta ilicitud) sino la omisión de retirarlos o de bloquear el acceso. Esto introduce un concepto ajeno al derecho del consumidor, originado seguramente por no considerar proveedor al sitio, ${ }^{11}$ aspecto que no se analiza en el fallo y que se resuelve como falta de legitimación pasiva sin referencia a un análisis de la existencia o no de una relación de consumo.

ción de la Directora General de Defensa y Protección de Consumidores y Usuarios de la Provincia del Chubut de fecha 17/08/2010 en el expediente administrativo No 1275/2008 S.T.R. R., D. A. c/ Mercado Libre.Com.Ar y/o quien resulte Responsable s/ Denuncia Ley de Defensa del Consumidor). ElDial.com - CC266E.

10 "La protección del consumidor actual requiere dar respuesta a la complejidad social, y por ello debe ser reformulada principalmente en campo del espacio virtual. El contacto del consumidor con los sistemas expertos es frecuente y particularizado, ya que se trata de conjuntos de logros técnicos o de experiencia profesional que organizan grandes áreas del entorno material y social en el que vivimos. Al subir a un avión no revisamos los controles del aeropuerto ni la capacidad del piloto; al contratar por Internet no hacemos una indagación sobre la solvencia del oferente o del servidor, el funcionamiento de las claves, el sistema de seguridad en las transacciones y otros aspectos. Siempre suponemos que alguien se ha ocupado de que las cosas funcionen; ese alguien no es un sujeto conocido y responsable de sus actos como ocurre con el almacenero del barrio, se trata, en cambio, de un sistema que puede aparecer ante el consumidor como una persona amable pero que es solo un empleado, de cara anónima y no responsable...” (Resolución Chubut, cit.).

11 "Mercado Libre es un sistema experto de comercialización de bienes y servicios, y sus obligaciones son las que le cabe a todo proveedor, conforme lo establecen los artículos $2^{\circ}, 10^{\circ}$ bis, $40^{\circ}$ y subsiguientes de la LDC” (Resolucion Chubut, cit.). 
Si hay relación de consumo, la responsabilidad es objetiva en términos del art. 40 Ley 24240. Ese es el punto de partida, sin necesidad de entrar en la discusión respecto a si la actividad de los hosting es riesgosa o no. Con estos basamentos, la Ley 24240 es concordante con la actual tendencia a la socialización del derecho de daños, garantizando un resarcimiento al damnificado por el solo hecho de estar afectado por la relación de consumo.

Merece extensión el tema del fundamento en el deber de seguridad. ${ }^{12}$ La vida en sociedad nos presenta, estemos o no conscientes de ello, como sujetos permanentemente expuestos a situaciones adversas sobre las que no podemos disponer, ni tener gobierno respecto a su acontecimiento o no, en razón que estamos social y permanentemente expuestos a aconteceres, sin tener responsabilidad, ni discernimiento, ni consciencia sobre lo que podía suceder, en ocasión de afectarnos algo por ser un sujeto meramente expuesto a la vida en sociedad y por ello, vulnerable a sus acontecimientos. En ese marco, emerge la teoría que formula la existencia de un riesgo creado por una acción u omisión en la sociedad, hoy caracterizada como de consumo, que hace al advenimiento de una concreta obligación de seguridad con entidad tal como para generar responsabilidad, caracterizando a la seguridad como uno de los pilares fundamentales de los contratos modernos. El carácter riesgoso de una actividad deviene de circunstancias extrínsecas, de persona, tiempo y lugar que la tornan peligrosa para terceros. La ponderación de estas circunstancias y su incidencia en el carácter riesgoso de la actividad debe realizarse en abstracto, independientemente del reproche que puede merecer la conducta del sindicado como responsable. La cuestión pasa por el grado de previsibilidad de la producción del daño a partir de la consideración de la naturaleza o circunstancias de la actividad, si hay una clara probabilidad de eventuales perjuicios funcionará el factor objetivo de atribución de ocurrir el daño. La temática que aquí nos convoca es la propia del sujeto que ni siquiera se entiende comprendido por una noción de riesgo, no teme por su seguridad, confía en las certezas y en la normalidad de los sistemas e instituciones que lo contornean. A su vez, la gratuidad (o lo que es lo mismo, la ausencia de cobro de comisión por parte de la demandada) no obsta a que exista relación de consumo ni a que sea considerada proveedor en términos del art. 1 de la Ley 24240. Se ha dicho con acierto que las páginas web que ofrecen acceso a información o contenidos de manera gratuita "se benefician con el acceso de usuarios $\mathrm{y}$ visitantes dado que venden espacios publicitarios mediante banners o logos o simplemente con un sistema de conteo de visitas". ${ }^{13}$

12 Véase Carlos Tambussi y María Eugenia D’Archivio, "La socialización del derecho de daños, el deber de seguridad y el expuesto a la relación de consumo", en Reparación integral de daños, dir. por Carlos A. Ghersi. Tomo III (Buenos Aires: Nueva Tesis, 2014), 11-39.

13 Véase Ezequiel Zabale,“Daños ocasionados en Internet”, LLNOA (mayo 2017): 5. 
Suele invocarse que la aplicación del factor objetivo haría responsables a los sitios de intercambio de todo daño producido a partir de sus anuncios y haría inviable su actividad, ya que deberían adoptar medidas de control y autorrestricción que producirían consecuencias masivas desde el plano constitucional, tratándose de una actividad lícita. ${ }^{14}$ Nos preguntamos, entonces: ¿por qué dejar el riesgo solamente para los consumidores y proteger a los proveedores? ¿Por qué considerar que es imposible que el sitio verifique la licitud y la seriedad de las operaciones que ofrece? No creemos que sea una imposibilidad práctica, dado que las plataformas pueden contemplar la exigencia de recaudos para las publicaciones, presentación de documentación previa a la aceptación del aviso, fianzas, u otros. De desligar a las plataformas de responsabilidad favorecemos a quien se beneficia sin tener que tomar ninguna precaución en aras de que sus beneficios no se obtengan a costa de avisos generadores de ilícitos. El único argumento es la celeridad del comercio y la imposición de la realidad tecnológica, que no debe ser resultante de írritas desprotecciones. La imposibilidad de control es solo una afirmación dogmática. De lo contrario se está llevando al comercio electrónico a autorregularse y a analizar la interpretación de su desenvolvimiento con total prescindencia de la vigencia del régimen tuitivo consumidor. Los que utilizan este medio para adquirir bienes o servicios son los consumidores. En este estado de la evolución tecnológica, es difícil afirmar que no existe obligación de los almacenadores de datos y portadores de la oferta de controlar el contenido que se ofrece en sus servidores. La supervisión debió haberse dado, y no se hizo, en oportunidad de recibir la publicación misma, produciéndose la inhabilitación después. Los indicios que se achacan como no percibidos por el consumidor corresponden al portal a la hora de su advertencia.

d) Otro punto es el argumento que a falta de regulación — recordemos, los hechos son anteriores a la vigencia del Código Civil y Comercial—, se funda el decisorio con base al derecho comparado que reseñamos supra. Ahí reside otro de los dilemas: la confusión entre derecho comparado y simplemente derecho extranjero. Si las instituciones estuvieran reguladas en nuestro país, podríamos entonces hablar de comparado. Pero el fallo aduce falta de legislación, y entonces simplemente invoca derecho extranjero. Y si se cae en eso, no debe olvidarse el contexto en que la normativa extranjera se aplica, sustancialmente diferente a la realidad de nuestros consumidores y en comprender "las razones históricas, jurídicas y culturales que han justificado el instrumento o texto jurídico analizado y entender las propias y las del contexto con las que se quiere comparar: solo así su tarea será eficaz".15

14 Véase Joaquín L. Abad, "Responsabilidad de los intermediarios de Internet (ISP) dedicados al comercio electrónico", Revista Argentina de Derecho Comercial y de los Negocios, n. ${ }^{\circ} 19$ (marzo de 2018): IJ-XDII-978.

15 Véase Alfredo Ferrante, "Entre derecho comparado y derecho extranjero. Una aproximación a la comparación jurídica", Revista Chilena de Derecho 43, n. 2 (agosto 2016). Allí se dijo también que "el trasplante jurídico no debe limitarse a 
Ahora bien: aunque los hechos del fallo ocurren bajo la vigencia del Código Civil derogado, si se trata de hacer aplicaciones supletorias, existen otros parámetros más cercanos y más aplicables que podrían haber sido utilizados. Y aun en ese terreno, como antecedente también europeo, en ese continente se ha adoptado desde 2007 el llamado "Libro Verde", para compras internacionales a partir de la web, a partir de los problemas generados por la contratación electrónica, que contiene normas sobre devolución de mercaderías, aumento de la protección de los consumidores en caso de incumplimientos de plazos, entregas parciales o incumplimientos, en un marco de amplitud de estas consideraciones protectorias. A su vez, el Mercosur tiene un régimen propio relativo a las contrataciones que efectúan los usuarios en materia de adquisición de bienes o servicios informáticos a través de Internet (Resolución 104/05 de la Secretaría de Coordinación Técnica de Defensa del Consumidor, que introduce la Resolución 21 del Grupo Mercado Común del Sur con fecha 8/10/04). Estas normas se aplican durante todo el proceso de transacción comercial y hacen especial hincapié en el derecho a la información clara, precisa y suficiente que debe garantizarse al consumidor. La norma es aplicable a todo proveedor radicado o establecido en alguno de los Estados parte del Mercosur.

La Organización de Cooperación y Desarrollo Económico (OCDE) en el marco de la Organización de las Naciones Unidas ha trabajado ampliamente en el comercio electrónico, en particular mediante las Directrices para la Protección de los Consumidores en el Contexto del Comercio Electrónico (1999), tomando como principios rectores: la protección transparente y efectiva (Sec. I), equidad en las prácticas empresariales, publicitarias y de mercadotecnia (Sec. II), información en línea (Sec. III) —que también incluye la información sobre la empresa, los bienes o servicios y las transacciones - así como el procedimiento de confirmación (Sec. IV) y los pagos (Sec. V) y ha elaborado orientaciones adicionales sobre el comercio móvil (las orientaciones de la OCDE sobre las nuevas cuestiones de protección y empoderamiento del consumidor en relación con aspectos del comercio electrónico), suplantación de identidad en línea (recomendaciones de la OCDE en materia de suplantación de identidad en línea) y los servicios de comunicación (recomendaciones de la OCDE para la protección y la emancipación de los consumidores de servicios de comunicación). ${ }^{16}$

una mera imitación, aunque esta puede de por sí — desde el punto de vista del análisis económico del derecho- traer beneficios, como reducir sensiblemente los costes de información o de investigación".

16 Ver Naciones Unidas TD/B/C.I /CLP/23, "Conferencia de las Naciones Unidas sobre Comercio y Desarrollo Distr. General”, 29 de abril de 2013, acceso el 10 de agosto de 2018, http://unctad.org/meetings/es/SessionalDocuments/ ciclpd23_es.pdf 
Por su parte, y también a manera de antecedente, la Resolución General 51/162 del 30 de enero de 1997 de la Asamblea General de las Naciones Unidas aprobó la Ley Modelo sobre Comercio Electrónico General, estableciendo que no deroga ninguna norma jurídica destinada a la protección del consumidor. Consumers International, por su parte, ha señalado que la legislación sobre comercio electrónico debe cumplir con los siguientes principios: a) A los consumidores que participan en el comercio electrónico se les debe entregar una protección transparente y eficaz, no menor al nivel de protección que se ofrece en las demás formas de comercio, b) Las empresas que participan con los consumidores por medio del comercio electrónico deben proporcionar información exacta, clara y fácilmente comprensible acerca de si mismos, los bienes y servicios que ofrecen, y los términos y condiciones en que estos son ofrecidos, a fin de permitir que los consumidores tomen decisiones informadas con respecto a aceptar o no la transacción) Para evitar las ambigüedades relacionadas con la intención de los consumidores de realizar una compra, el consumidor debe poder, antes de concluir la compra, identificar de manera precisa los bienes y servicios que comprará; identificar y corregir cualquier error o modificar el orden; expresar su consentimiento deliberado e informado para la compra; y conservar un registro completo y exacto de la transacción, d) Se debe proporcionar a los consumidores mecanismos de pago seguros y fáciles de usar e información sobre el nivel de seguridad que brindan dichos mecanismos, d) Los productos digitales deben ofrecerse en términos equivalentes a aquellos que se venden en otros formatos, a menos que los consumidores estén claramente informados de que los términos que aplican son diferentes. Esto incluye las incidencias normales de propiedad de los productos, tales como posesión permanente, privacidad del uso, la posibilidad de obsequiar o revender dichos productos junto con todos los derechos con los cuales fueron vendidos por primera vez, y la posibilidad de préstamo o uso de estos dentro de una familia, hogar o círculo limitado similar. Para facilitar estos, y para permitir que el consumidor tenga acceso a estos en un momento y lugar convenientes, los Gobiernos deben permitir a los consumidores el tiempo, espacio, y el cambio de formato en los productos de contenido digital, realizar copias provisionales de estos, y omitir las medidas técnicas de protección aplicadas a estos. Impedir el ejercicio de estos derechos debe estar prohibido por la ley. En la medida de lo posible, los consumidores deben tener la oportunidad de probar un producto de contenido digital antes de realizar la compra.

e) En cuanto al cumplimiento del deber de información, consideramos que es insatisfactorio su cumplimiento si la brindada por Mercado Libre se limita a avisar que se deslinda de la responsabilidad. Los consumidores carecen de los conocimientos necesarios para poder juzgar tanto por adelantado como sobre la marcha de negocios complejos, sus características intrínsecas, sus cualidades o defectos, conocer los riesgos de uso o consumo y las medidas a adoptar para evitarlos y es el proveedor quien debe comportarse como buen hombre de negocios en su profesionalidad en el marco de la 
relación de consumo, para lo cual no se hace distingo de la mecánica operatoria, que en estos casos, rigoriza los deberes del sitio en cuanto a información al consumidor como también al control de lo que se ofrece en su espacio.

f) Cabe agregar que finalizando sus argumentos el fallo se refiere a que el actor pretende sacar provecho de la alegación de su torpeza, lo cual no resiste análisis desde el momento en que pretende la reparación de los daños y la restitución de lo pagado. El pensar que el consumidor quiere enriquecerse es muchas veces una marca de fábrica argumental cuando se decide una cuestión que involucra a consumidores con principios ajenos al régimen tuitivo consumidor. No habría ningún provecho para el actor en el caso de hacerse lugar a la demanda.

g) La misma directiva 2000/31/CE del Parlamento Europeo, citada en el fallo, respecto de la información exigida para el comercio electrónico, dice en su artículo 10 (resaltado nuestro): Información exigida: 1. Además de otros requisitos en materia de información contemplados en el Derecho comunitario, los Estados miembros garantizarán, excepto cuando las partes que no son consumidores asi los acuerden, que el prestador de servicios facilite al menos la siguiente información de manera clara, comprensible e inequivoca y antes de que el destinatario del servicio efectúe un pedido: a) los diferentes pasos técnicos que deben darse para celebrar el contrato; b) si el prestador de servicios va a registrar o no el contrato celebrado, y si este va a ser accesible; c) los medios técnicos para identificar y corregir los errores de introducción de datos antes de efectuar el pedido; d) las lenguas ofrecidas para la celebración del contrato.

Por lo que tenemos al menos, una lectura sesgada de la Cámara al citar esta Directiva, a, menos en su faceta más liberal, no tan correspondiente con su sentido o finalidad. $\mathrm{Y}$ aunque no vigente por razones temporales, hubiésemos esperado una saludable interpretación de las normas del Código Civil y Comercial de la Nación sobre comercio electrónico: Art. 1107. Información sobre los medios electrónicos. Si las partes se valen de técnicas de comunicación electrónica o similares para la celebración de un contrato de consumo a distancia, el proveedor debe informar al consumidor, además del contenido mínimo del contrato y la facultad de revocar, todos los datos necesarios para utilizar correctamente el medio elegido, para comprender los riesgos derivados de su empleo, y para tener absolutamente claro quién asume esos riesgos.

Esta norma para los contratos electrónicos enlaza con el deber de información que la Ley 24240 establece en el Art. 34. Este deber ha de ser satisfecho antes que el sistema de la contratación por la Web imponga al consumidor la aceptación de los términos y condiciones y en su cumplimiento, el empresario deberá facilitar de forma clara y comprensible, y en esa oportunidad, la información relevante, veraz y suficiente sobre 
las características principales del contrato, sus condiciones jurídicas y económicas. Así se ha resuelto en la jurisprudencia comparada. ${ }^{17}$

h) Lorenzetti, que es citado en el fallo para fundar la eximición de "obligaciones proactivas" a cargo del alojador/intermediario, también ha dicho, respecto a los sistemas de comercialización ${ }^{18}$ : "En la sociología actual se ha estudiado el funcionamiento de los "sistemas expertos", los que son calificados como sistemas de logros técnicos o de experiencia profesional que organizan grandes áreas de entorno material y social en el que vivimos. Al subir a un avión no revisamos los controles del aeropuerto ni la capacidad del piloto; al contratar por internet no hacemos una indagación sobre la solvencia del oferente, del servidor, el funcionamiento de las claves, el sistema de seguridad en las transacciones, y otros aspectos". Y en cuanto a la previsión aguda que se exige al consumidor en este fallo, podemos aplicar estos dichos del presidente de la Corte Suprema: "Siempre suponemos que alguien se ha ocupado de que las cosas funcionen. Ese alguien no es un sujeto conocido y responsable de sus actos, como ocurre con el almacenero del barrio; se trata en cambio de un sistema, que puede aparecer ante el consumidor como una persona amable, pero que es solo un empleado, cara anónima y no responsable. El sistema es inextricable porque la complejidad técnica que presenta es abrumadora; es anónimo porque no se puede conocer el dueño ni al responsable. Sin embargo, el sistema genera fiabilidad a través de su funcionamiento reiterado, las marcas, el respaldo del Estado y otros símbolos". "Las pruebas que realiza el consumidor para verificar la seriedad son muy pocas y generalmente inicuas; se basa en un conocimiento inductivo débil. No se trata de un problema de negligencia, sino de una necesidad: si se tuviera que verificar razonablemente cada acto, sería imposible vivir, y los costos de transacción serían altísimos”. Es claro que al débil se le hace más difícil supervisar.

\section{COMPETENCIA EN COMERCIO ELECTRÓNICO}

a. Normativa sobre la jurisdicción aplicable: El artículo 1109 del Código Civil y Comercial establece que "en los contratos celebrados fuera de los establecimientos comerciales, a distancia, y con utilización de medios electrónicos o similares, se considera lugar de cumplimiento aquel en el que el consumidor recibió o debió recibir la prestación. Ese lugar fija la jurisdicción aplicable a los conflictos derivados del contrato. La cláusula de prórroga de jurisdicción se tiene por no escrita”.

17 "Es insuficiente para ser considerados como aceptados, los términos y condiciones de contratación que solo figuran al pie de la "homepage" de un sitio de Internet y conforme a los cuales todo el que pase la página inicial presta su consentimiento. Máxime si el titular del sitio ni incluyó una ventana de aceptación que el usuario deba cliquear antes de proseguir con la consulta de la web" (Tribunal Federal de California, Ticketmaster Corp. et al. c. Tickets.Com, Inc. 27/03/2000 en La Ley On Line Cita: AR/JUR/443/2000).

18 Ricardo Lorenzetti, “Comercio electrónico y defensa del consumidor", La Ley (2000-D): 1003. 
El considerado como lugar de cumplimiento debe ser el domicilio real del consumidor o el que expresamente este haya indicado. De lo contrario, se permitiría imponer lugares de entrega desventajosos para el consumidor, que en los hechos importen una indirecta prórroga de la competencia. La determinación de la jurisdicción hace tanto a las posibilidades de acceso a la justicia como a la vigencia efectiva y posible de la garantía de defensa en juicio. El codificador legisló al respecto en la Sección 12 "Contratos de Consumo" (art. 2654), donde determinó:

Las demandas que versen sobre relaciones de consumo pueden interponerse, a elección del consumidor, ante los jueces del lugar de celebración del contrato, del cumplimiento de la prestación del servicio, de la entrega de bienes, del cumplimiento de la obligación de garantía, del domicilio del demandado o del lugar donde el consumidor realiza actos necesarios para la celebración del contrato. También son competentes los jueces del Estado donde el demandado tiene sucursal, agencia o cualquier forma de representación comercial, cuando estas hayan intervenido en la celebración del contrato o cuando el demandado las haya mencionado a los efectos del cumplimiento de una garantía contractual. La acción entablada contra el consumidor por la otra parte contratante solo puede interponerse ante los jueces del Estado del domicilio del consumidor. En esta materia no se admite el acuerdo de elección de foro.

De forma que el consumidor actor tiene un menú de opciones, y el consumidor demandado solo puede serlo ante el juez con jurisdicción en su domicilio, siendo nulo (abusivo) por expresa disposición legal el "acuerdo de elección de foro" el cual, sabemos, nunca participa de la naturaleza ontológica de "acuerdo" sino que resulta impuesto en contrataciones por adhesión.

En lo atinente al derecho aplicable a los contratos de consumo internacionales, ellos se rigen por el del Estado del domicilio del consumidor en las siguientes situaciones (art. 2655):

1.- Cuando la conclusión del contrato fue precedida de una oferta o de una publicidad o actividad realizada en el Estado del domicilio del consumidor y este ha cumplido en él los actos necesarios para la conclusión del contrato. 2.- Si el proveedor recibió el pedido en el Estado del domicilio del consumidor. 3.- Si el consumidor fue inducido por el proveedor a desplazarse a un Estado extranjero a los fines de efectuar en él su pedido. 4.- $\mathrm{Si}$ los contratos de viaje comprenden prestaciones combinadas de transporte y alojamiento por un precio global.

Fuera de ello, los contratos de consumo se deben regir por el derecho del país del lugar de cumplimiento. Si no se puede determinar el lugar de cumplimiento, el contrato se rige por el derecho del lugar de celebración. 
b. El caso "Pérez Morales": ${ }^{19}$ Tuvo la suerte el actor que le haya tocado en suerte un cyberproveedor con filial nacional ya que que conforme la página de Booking.com se remite en forma general el planteo de controversias a la jurisdicción de Amsterdam. En efecto, el fallo de Cámara parte del dato cierto que es la dificultad de hallar una pauta valida que determine la jurisdicción competente en un contrato celebrado en el ciberespacio y a tal evento, formula una solución. Esta se basa en que existe "un punto de conexión" con domicilio real, que es del de la filial argentina del demandado Booking.com Argentina SRL. Ello así, coincida o no con el sufijo geográfico (ar, br, fr, es, etc.) de la dirección electrónica o virtual. Dicho esto en razón que del decisorio se desprende que el proveedor argumentó la jurisdicción extranjera aplicable al caso y por ende el planteo de incompetencia, en razón de la ubicación en Holanda del server que permite la conexión o la localización física de sus computadoras. Acertadamente el fallo enuncia que, de ser así, se permitiría migrar permanentemente la ubicación de los ordenadores y/o del punto de conexión y de esa manera eludir la acción de la justicia, generándose inseguridad jurídica en el comercio electrónico. Sepamos que el proveedor demandado en estos autos intentó la generación de ese fenómeno. ${ }^{20}$

Y dejó dicho el tribunal que en los casos en que resulte difícil o imposible ubicar al demandado, si existen suficientes elementos que lo vinculen con nuestro país, la norma debe interpretarse ampliamente y recibir el caso jurisdicción argentina, por aplicación del llamado foro de necesidad (art. 2602 CCC) a fin de evitar lo que llama una denegación internacional de justicia. ${ }^{21}$

Antes dijimos que el consumidor en este caso fue afortunado, dada la existencia de una filial argentina y de esa manera estar alcanzado por el párrafo segundo del art. 2654 que refiere a la existencia de "sucursal, agencia o cualquier forma de representación comercial”, y podrá reclamar sus derechos ante jueces argentinos. Así, se aplica el art. 2654 con su sentido esencialmente protectorio, al conferir el abanico de posibilidades antes reseńado al consumidor actor, y ser más estricto y severo frente al caso del consumidor demandado. Sin embargo, la doctrina señala que entre el menú de opciones del art. 2654 está ausente, llamativamente, la posibilidad directa que el

19 Gonzalo Martín Pérez Morales c/ Booking.com Argentina SRL y otros s/ ordinario, Cámara Nacional de Apelaciones en lo Comercial, Sala C, 10/08/2017 en DPI Cuántico, Diario de Derecho de Consumidores y Usuarios, No 129 -29.08.2017.

20 Del fallo de primera instancia conocemos que Booking Argentina negó haber tenido intervención en la contratación y que el titular de la página web es una empresa de nombre similar que tiene domicilio en Holanda. De seguirse esa lógica, debió haber planteado una excepción de falta de legitimación pasiva.

21 Dice el art. 2602: "Aunque las reglas del presente código no atribuyan jurisdicción internacional a los jueces argentinos, estos pueden intervenir excepcionalmente con la finalidad de evitar la denegación de justicia siempre que no sea razonable exigir la iniciación de la demanda en el extranjero y en tanto la situación privada presente contacto suficiente con el país, se garantice el derecho de defensa en juicio y se atienda a la conveniencia de lograr una sentencia eficaz". 
consumidor accione ante los jueces de su propio domicilio. ${ }^{22}$ Esta posibilidad — de existir en el futuro a través de una reforma legislativa - nos obligaría a pensar acerca de la factibilidad técnica y temporal de una demanda desde la Argentina contra una matriz o sucursal extranjera, y las posibilidades de una eventual ejecución de una también eventual decisión favorable. Ese es el gran peligro de las contrataciones web, que no es menor. Colocar al consumidor a merced de proveedores lejanos, nómadas o fantasmas. Mientras no existan en forma efectiva acuerdos empresariales internacionales de solución de controversias extrajudiciales, tratados resultantes de la cooperación internacional, ${ }^{23}$ o regulaciones internas que obliguen a los proveedores web que oferten en el país a establecer algún tipo de anclaje territorial en la Argentina (sucursal, domicilio, caución, u otros), a la hora de controversias con los sitios transnacionales el consumidor corre un fuerte riesgo de indefensión.

La postulación de la necesidad de regulaciones internas será seguramente criticada con el argumento remanido de la celeridad del comercio y la maravilla del mundo de posibilidades que ofrece la contratación web que se vería de esa manera afectado en su desenvolvimiento. Sin embargo, la recomendación de formulación de políticas estatales al respecto - esto es, por su nombre, intervención del Estado a través del imperium regulador, es parte de las propuestas de las "Directrices de las Naciones Unidas para la Protección del Consumidor", formuladas por la Asamblea General en la Resolución $70 / 186$ del 22 de diciembre de $2015 .^{24}$

Sin regulación rigurosa por parte del poder público, seguiremos sorprendiéndonos con la liberalidad de estos sitios. Es interesante señalar cómo la demandada hace esquizofrénica su propia personalidad: pertenece a una gran red mundial de reservas hoteleras por web, pero su filial argentina — según su argumentación — es parte de otro universo jurídico, una persona distinta y ajena a la contratación. A su vez,

22 "Llama la atención que en un listado tan amplio no figure la opción del domicilio del consumidor. Si bien, varias de las numerosas opciones dadas por el art. 2654 producirán, en los hechos, que el consumidor demande ante los tribunales de su domicilio, hubiese sido más razonable prever directamente esa opción a fin de evitar cualquier dificultad de acceso a la justicia por parte del mismo" (Demetrio Alejandro Chamatropulos, "Estatuto del Consumidor Comentado", La Ley (2016).

23 Dentro de este conjunto de reglas estaría un código legislativo que regulase el comercio electrónico a escala internacional, aplicable a las transacciones internacionales por todos los países, vía tratado internacional o Código de Conducta en Internet, netiquettes, políticas de usos en la red (Internet Use Policies), regulaciones de proveedores de acceso a Internet, normas deontológicas, principios básicos de e-business, etc. (Antonio Díaz Bermejo, "La resolución internacional de controversias en el comercio electrónico", acceso el 25 de febrero de 2018, http://noticias.juridicas.com/conocimiento/ articulos-doctrinales/4440-la-resolucion-internacional-de-controversias-en-el-comercio-electronico/

24 Directrices de las Naciones Unidas. Sección I. Comercio electrónico. 63. Los Estados Miembros deben esforzarse por fomentar la confianza de los consumidores en el comercio electrónico, mediante la formulación constante de políticas de protección del consumidor transparentes y eficaces, que garanticen un grado de protección que no sea inferior al otorgado en otras formas de comercio. 
intenta deshacerse del conflicto refiriendo a que los hoteles reservados también se encuentran en Europa. Aunque el concepto jurídico de "lugar" para determinar competencias sea discutido en el comercio electrónico, dado lo etéreo del ciberespacio, que la oferta del sitio web (o direccionador) sea alcanzable en un país determinado, hace aplicable su normativa y jurisdicción. La ajenidad y el altruismo son argumentos recurrentes de los portales. Bombardean con la confianza de la practicidad y la agilidad, pero en sus contestaciones jurídicas afirman que de por sí no prestan ningún servicio ${ }^{25}$ al consumidor: en el caso del buscador hotelero, dicen que la búsqueda es gratuita y el contrato de hospedaje le es ajeno. Invocan luego que los términos y condiciones fueron aceptados y que su publicidad no es inductiva o motivante del ingreso del consumidor a la contratación por ese medio. No se atreven a decir que eso se produce porque su nombre y posición en el mercado generan presuntivamente ese impulso a partir de la confianza, que es lo que defraudan. En su reino, califican a su antojo las reservas como cancelables o no cancelables con o sin costo, e imponen para su mantenimiento muchas veces el pago anticipado. Reniegan y no informan del derecho al arrepentimiento, aunque sean páginas web nacionales. Carecen de interlocutores humanos y niegan su conexión con la casa matriz — si la hubiere- a la hora de las responsabilidades. Inundan posteriormente al consumidor con nuevas propuestas para los servicios una vez buscados mediante la remisión de avisos no deseados.

De modo que la internacionalización que implica el comercio electrónico, si no es debidamente regulada, puede favorecer solamente a los proveedores, o ser para ellos un excelente negocio. Por esa razón debe considerarse que el pago hecho desde la jurisdicción del consumidor, el uso de la tarjeta y un banco local para la transferencia, importan actos que implican la intención del demandado de dirigir su actuación al Estado donde se radica el pleito, si es que no se acepta la mera accesibilidad de un anuncio de internet en ese lugar. De todas formas, el tema no debe verse con los criterios generales, sino que para el caso de consumidores la cuestión toma un cariz diferente, ya que demandar en su jurisdicción a un contrincante extranjero no será de por sí una tarea fácil, pero litigar en extraña jurisdicción eventualmente transoceánica le resultaría directamente imposible. El consumidor paga a priori y queda a la espera que un proveedor cumpla con lo que ya ha pagado. Esa desventaja palmaria, en caso de controversia debe poder saldarse en jurisdicción del consumidor.

25 Una reseña muy ilustrativa de los fundamentos de la contestación de demanda puede verse en Carolina Iud, "La jurisdicción internacional en contratos electrónicos concluidos por consumidores”, La Ley On Line, AR/DOC/3211/2017. 


\section{INCUMPLIMIENTO DEL DERECHO DE ARREPENTIMIENTO.}

El caso "LAN": ${ }^{26}$ En este precedente, consistente en un cuestionamiento judicial de multa aplicada por la autoridad administrativa, se decidió por la confirmación de la sanción, al surgir "con claridad que la facultad de revocar la aceptación dentro de los diez días de suscripto el contrato por vía electrónica, debe incluirse en forma clara y notoria en aquel, y el incumplimiento se verifica pues no surge la opción incluida en las condiciones de venta del ticket aéreo, ni informado el medio establecido a efectos de ejercerla". Con lo que se puso de manifiesto el incumplimiento por parte de la línea aérea del deber de informar al consumidor la posibilidad de ejercer el derecho al arrepentimiento, dispuesta por el Código Civil y Comercial de la Nación. Quedó como resultado de la verificación probatoria que el consumidor quiso rechazar la compra del ticket aéreo, pero que sin embargo no se le permitió ejercer su derecho.

Existe además un componente muy particular de la contratación electrónica: la confusión entre la línea aérea y su filial local, habiendo sido citada la primera y respondido la segunda acudiendo a las instancias conciliatorias en sede administrativa, intentó luego en sede judicial, al cuestionar la multa, volver a separar las identidades. Es así que se consideró que "el acto de presentarse y estar a derecho sin informar supuestos errores o diferencias directamente vinculados con la identidad del sujeto pasivo de los hechos enunciados resulta una conducta jurídicamente relevante, contra la cual no puede ponerse en contradicción sin lesionar la buena fe; máxime siendo que la situación impone un deber de coherencia del comportamiento, que consiste en la necesidad de observar en el futuro la conducta que los actos anteriores hacían prever".

El estudio de este caso puede completarse con el precedente donde se analizó la conducta empresaria de desconocer contra legem el ejercicio del derecho al arrepentimiento en las condiciones generales impuestas. ${ }^{27}$

26 Cámara Nacional de Apelaciones en lo Contencioso Administrativo Federal, sala IV, "Lan Airlines S.A. c/ DNCI s/ defensa al consumidor - Ley 24.240", 22-dic-2015, Microjuris, cita: MJ-JU-M-96502-AR | MJJ96502 | MJJ96502.

27 Cámara 4a de Apelaciones Civil y Comercial de Córdoba, 22/02/2017, "Álvarez F. c. Falabella S. A", en DPI Cuántico, Diario de Consumidores y Usuarios Nro. 110, del 28/03/2017. En dicho fallo, además, se determinó que el uso de la cosa adquirida por comercio electrónico — en este caso una tablet- no obsta al ejercicio válido del derecho al arrepentimiento, pese a que las previsiones reglamentarias (Dec. 1798/93) determinan que la cosa recibida no puede usarse. Se hace así prevalecer la interpretación más favorable al consumidor y a la norma sustantiva por sobre la reglamentaria, en la inteligencia de admitir el uso del bien durante el plazo para ejercer el arrepentimiento, como única alternativa para el consumidor de verificar la utilidad del producto como acorde a las características esperadas, a sus necesidades u otros aspectos tenidos en cuenta al tiempo de adquirirlo. 


\section{EL DERECHO ADMINISTRATIVO SANCIONATORIO}

En el caso que analizamos, la sala I de la Cámara Contencioso Administrativo y Tributario de la Ciudad Autónoma de Buenos Aires ${ }^{28}$ nos trae una nueva experiencia desde el derecho administrativo sancionatorio respecto a este tipo de emprendimientos. Le toca resolver un caso de denuncia ante la autoridad de aplicación por parte de una consumidora que sufrió un incumplimiento en la entrega de un producto adquirido en esa plataforma de ventas, además de la falta de información respecto de los datos del vendedor del producto. Este consistió en sándwiches de miga abonados con tarjeta de crédito a través del sitio de Mercado Libre, que no fueron entregados, por lo que solicitó un resarcimiento en concepto de daño directo. Es importante destacar el resultado negativo de la etapa conciliatoria, y el resultado final del sumario infraccional en la imposición de una multa de treinta mil pesos a la empresa infractora.

Para así decidir hace mérito del pago a través de la cuenta registrada de la proveedora que Mercado Libre gestiona como mandataria del proveedor, siendo tal rol el que la hace parte de la cadena de compraventa y protagonista de la relación de consumo. Respecto de la negativa de brindar datos adicionales sobre el vendedor, es entendido como una violación al deber de información y una contribución al amparo en el anonimato para infringir la ley, del que no se desliga el sitio por su condición de intermediario.

La referencia respecto al tratamiento de los agravios referidos a la condición de proveedor de Mercado Libre y su "no ajenidad" aparecen como tratados en el dictamen del fiscal de Cámara, que no se reproduce en el fallo, al cual remite. Lo mismo con relación al incumplimiento del deber de información. No obstante, el decisorio refiere a la concepción amplia de la relación de consumo, que fuera desarrollado en el precedente "Claps", ya referenciado, como comprensiva de toda actividad encaminada a satisfacer la demanda de bienes y servicios. Alude también a la esfera de confianza creada, como herramienta para atraer clientes y propicia en el voto de la doctora Mariana Díaz, el rechazo del cuestionamiento de la sanción.

Se detiene el voto en lo relativo a la sanción impuesta, calificada de desproporcionada e irrazonable por la recurrente en forma dogmática sin críticas serias y fundadas, por lo que propicia también el rechazo de ese agravio. Para así decidir, señala que el criterio graduador basado en el "perjuicio resultante de la infracción para el consumidor o usuario" (que, como dijimos, obtuvo una restitución parcial de lo pagado) constituye un parámetro valido, pero no excluyente para determinar la cuantía de la multa, que no aparece carente de motivación

28 Cámara de Apelaciones en lo Contencioso Administrativo y Tributario de la Ciudad Autónoma de Buenos Aires, sala I, 11/06/2018, "Mercado Libre SRL c. Dirección General de Defensa y Protección al Consumidor s. recurso directo", en La Ley On Line, cita AR/JUR/24534/2018. Ver nuestra opinión en Carlos Tambussi, "Sobre las plataformas de comercio electrónico y el derecho sancionatorio en materia de consumo", ERREIUS Temas de Derecho Comercial, Empresarial y del Consumidor (agosto/2018), cita digital IUSDC286065A. 
o desproporcionada, teniendo en cuenta que además se invoca la posición en el mercado del infractor y su carácter de reincidente. Cae la desproporcionalidad teniendo en cuenta el monto aplicado — treinta mil pesos - y el mínimum de 100 pesos y el máximo de cinco millones que permite el art. 47 de la Ley de Defensa del Consumidor.

El voto del Dr. Carlos Balbín profundiza en cuanto al alcance de la Ley 24240 al caso de Mercado Libre ya que brinda un servicio al consumidor. En ese marco, toma la cuestión relativa a la falta del deber de información, escudándose en no estar autorizada a suministrar datos del vendedor. Agrega que en el marco del Mercosur, la normativa para comercio electrónico (Res. SCT 104/2005) expresamente establece el derecho del consumidor a una información clara, precisa, suficiente y de fácil acceso sobre el proveedor del producto o servicio. Valga esto, agregamos, para el comercio ofrecido por el proveedor directo como para las "plataformas". Rechaza el argumento de la protección de datos, que no están amparados por confidencialidad alguna, no encontrando razones para el ocultamiento de informes como domicilio, razón social o inscripción impositiva de los vendedores, en base a elementales principios de buena fe, siendo además contenidos obligatorios desde el punto de vista fiscal y de la ley de defensa del consumidor en los documentos de venta. Por último, menciona el elemento confianza que hemos apuntado supra, y el valor transparencia que - al desaparecer por el ocultamiento - coloca al consumidor en una vulnerabilidad mayor a la natural y a la acentuada en el sistema de comercio electrónico, considerando el valor normativo de las Directrices de Naciones Unidas para la Protección del Consumidor que se refieren específicamente al caso.

Los proveedores son los que tienen la imposición de cumplir con el régimen tuitivo consumidor, en el marco compuesto por la ley 24240, el Código y las leyes especiales de actividades o servicios, y están sujetos a sus obligaciones y responsabilidades, sean personas humanas o jurídicas, públicas o privadas. Mercado Libre es un proveedor en los términos del art. 2 de la Ley de Defensa del Consumidor. Pone al alcance de un número indeterminado de posibles clientes registrados los bienes y servicios que otros producen u ofrecen, percibiendo beneficios también por publicitar y por cada transacción que se concrete. La referencia a normas de tratados de integración y a las Directrices de las Naciones Unidas: consideramos saludable la mención en el voto del Dr. Balbín, como fundamento en derecho, de normas del tratado de integración del MERCOSUR, uno de los más propicios ámbitos para el desarrollo jurídico de la protección de estos derechos, formulando iniciativas de políticas y acciones que hagan a la sostenibilidad política, social, económica y ambiental de las sociedades.

Nacido del Tratado de Asunción (26 de marzo de 1991), en 1993 en el marco del Subgrupo de Trabajo Nro. 10, el Grupo Mercado Común creó una Comisión de Defensa del Consumidor, con representantes oficiales, sin intervención de empresarios, ni asociaciones de consumidores. La tarea consistió, primeramente, en la comparación de las legislaciones de los 
cuatro países, analizando sus asimetrías y elaborando propuestas concretas de armonización. A fines del ańo 1994, en el Protocolo de Ouro Preto, se modificó la estructura institucional del Mercosur, creándose, entre otras, una Comisión de Comercio Mercosur. Esta dispone, por Resolución 1/95, la constitución del Comité Técnico No. 7 Defensa del Consumidor. Por Resolución de Grupo Mercado Común No. 126/94 se dispuso que la Comisión prosiga los trabajos de elaboración de un Reglamento común para la defensa del consumidor. En reunión de mediados de 1996, se resolvió, para registrar avances, aprobar algunos capítulos del Reglamento. Se aprobaron las Resoluciones del Grupo Mercado Común No.123 a 127/96 el 13.12.96 referentes a conceptos, derechos básicos, protección de la salud y seguridad del consumidor, publicidad y garantía contractual. En cuanto a los conceptos fundamentales, se aprobaron los referentes al consumidor, proveedor, relación de consumo y producto. La referencia a sus normas sobre comercio electrónico constituye una verdadera puesta en valor por la jurisprudencia de la fuente normativa y protectora proveniente de este tratado de integración. En cuanto a las Directrices de las Naciones Unidas ${ }^{29}$, aprobadas por la Asamblea General de la Organización de las Naciones Unidas en 1985, Resolución 39/248, ampliadas en 1999, enumeran expresamente cuáles son los derechos de los consumidores y usuarios, la obligación de proveer a la protección de los mismos por parte de las autoridades propiciando legislación que reconozca a los mismos y permita su intervención para esos fines.

\section{CIERRE}

En el pasado día mundial del consumidor, el 15 de marzo de 2018, Consumers International hizo un llamado a mercados digitales más justos. El camino es largo por recorrer, para que el consumidor electrónico tenga una protección más profunda que la que tienen otras maneras de acceder a las relaciones de consumo. Es necesario que se ponga un énfasis profundo en el derecho a la información, sobre todo en cuanto a claridad y comprensión, y respecto de las posibilidades que tenga el consumidor de arrepentirse de la compra, los efectos de la misma y de conservar constancias de las transacciones, más allá de las que correspondan al pago.

Dadas las cualidades de la contratación por Internet, la rigurosidad en la satisfacción del deber de información que ha de cumplir el proveedor resulta destacable, imprescindible y necesaria, ya que él es quien ha diseñado la oferta, el que almacena o conserva toda la información a su respecto en la página web, y quien decide sin posibilidad de réplica qué es lo que quiere exhibir, declarar o manifestar respecto de lo que está ofreciendo, a través de un mecanismo de propuesta unilateral, que podemos caracterizar como una verdadera "adhesión virtual”. Además, la tecnología puede ser excluyente, dado que para perfeccionar una contra-

29 Véase Carlos Tambussi, "Juntos a la par: las normas sobre comercio electrónico en el nuevo Código y la proyectada ampliación de las Directrices de Naciones Unidas para la Defensa del Consumidor”, Jurisprudencia Argentina JA 2015-IV-4: 3-10. 
tación se requieren conocimientos, habilidades o "experiencia" informática, que no todas las personas de todas las edades están en condiciones de reunir. Las oportunidades u ofertas por Internet, en este sentido, dejan "fuera" a quienes no indagan o buscan ocasiones de consumos por este medio, simplemente porque no saben manejarlo, o aun sabiéndolo, reniegan de las dificultades de su implementación.

El principio de consentimiento informado y la posibilidad del consumidor de conservar registro "completo y exacto" del negocio celebrado, debe ser una pauta a incluirse en una futura modificación legislativa, en el sentido de ampliar la protección en este punto, a fin de no centrar la cuestión en depender de lo que el proveedor tenga a bien guardar o registrar en su página, y de la aplicación del principio de las cargas dinámicas de la prueba (uso de formatos y protocolos abiertos).

El futuro llegó hace rato. Hablamos entonces de un tipo de comercio generalizado, anómico hasta hace muy poco, de difícil o incomprensible acceso para los que no comprenden el mundo informático, y muy utilizado por los proveedores para conductas de captación de clientes, marketing y maximización de beneficios, muchas veces lindera con aspectos que transitan entre el engańo y el abuso, explotando la confianza puesta por el consumidor, la impersonalidad del trato, y sobre todo, la primigenia irreversibilidad de los pagos que reciben.

La magistratura activa cuenta con herramientas para proteger a los consumidores. Es necesario que a este protagonismo lo acompańe el desarrollo normativo y también y como siempre, la responsabilidad social empresaria que entienda que el derecho del consumidor viene a equilibrar y a nivelar, a proteger el mercado, y que el mejor camino que pueden encarar es el buen trato y la fidelización del cliente. El momento en que esto se entienda, significará que el derecho de usuarios y consumidores ha comenzado a encarnar culturalmente, dejando de ser un clamor unilateral.

\section{REFERENCIAS}

- Abad, Joaquín L. "Responsabilidad de los intermediarios de Internet (ISP) dedicados al comercio electrónico". Revista Argentina de Derecho Comercial y de los Negocios, n. ${ }^{\circ} 19$ (marzo de 2018): IJ-XDII-978.

- Barocelli, Sergio Sebastián. "Los sujetos expuestos a una relación de consumo". DJ $(11 / 05 / 2011)$. 
- Chamatropulos, Demetrio Alejandro. "Estatuto del Consumidor Comentado". La Ley (2016).

- Díaz Bermejo, Antonio. "La resolución internacional de controversias en el comercio electrónico". Acceso el 25 de febrero de 2018. http://noticias.juridicas.com/conocimiento/ articulos-doctrinales/4440-la-resolucion-internacional-de-controversias-en-el-comercio-electronico/

- Feldstein de Cárdenas, Sara Lidia. "Desprotección del consumidor transfronterizo. Hitos en el derecho latinoamericano contemporáneo". La Ley (18/03/2015).

- Ferrante, Alfredo. "Entre derecho comparado y derecho extranjero. Una aproximación a la comparación jurídica”. Revista Chilena de Derecho 43, n. 2 (agosto 2016).

- Gilbota Landriel, Verónica. "El comercio electrónico y la defensa del consumidor". DJ $(10 / 11 / 2010)$.

- Iud, Carolina. "La jurisdicción internacional en contratos electrónicos concluidos por consumidores". La Ley On Line, AR/DOC/3211/2017.

- Lorenzetti, Ricardo. "Comercio electrónico y defensa del consumidor". La Ley (2000-D).

- Maximiliano Calderón, José Fernando y Rafael Márquez. "El arrepentimiento en el derecho del consumo". La Ley (2009-C).

- Naciones Unidas TD/B/C.I /CLP/23. "Conferencia de las Naciones Unidas sobre Comercio y Desarrollo Distr. General”, 29 de abril de 2013. Acceso el 10 de agosto de 2018. http://unctad.org/meetings/es/SessionalDocuments/ciclpd23_es.pdf

- Tambussi, Carlos y Lucrecia Córdoba. "Y los libres mercados responden (A propósito de los sitios de compraventa en Internet)". Microjuris (21/12/2012): MJ-DOC-6121-AR | MJD6121.

- Tambussi, Carlos. "Relación de consumo y responsabilidad objetiva entre los usuarios de las plataformas de venta y el proveedor del servicio". La Ley (22/05/201).

- Tambussi, Carlos y María Eugenia D’Archivio. "La socialización del derecho de daños, el deber de seguridad y el expuesto a la relación de consumo". En Reparación integral de daños, dir. por Carlos A. Ghersi, 11-39. Tomo III. Buenos Aires: Nueva Tesis, 2014.

- Tambussi, Carlos. "Sobre las plataformas de comercio electrónico y el derecho sancionatorio en materia de consumo". ERREIUS Temas de Derecho Comercial, Empresarial y del Consumidor (agosto/2018). Cita digital IUSDC286065A. 
- Tambussi, Carlos. "Juntos a la par: las normas sobre comercio electrónico en el nuevo Código y la proyectada ampliación de las Directrices de Naciones Unidas para la Defensa del Consumidor". Jurisprudencia Argentina JA 2015-IV-4.

- Zabale, Ezequiel. "Dańos ocasionados en Internet”. LLNOA (mayo 2017).

RECIBIDO: $17 / 08 / 2018$

APROBADO: $15 / 10 / 2018$ 